\title{
Políticas de produção de conhecimento em enfermagem
}

\author{
Policies for nursing knowledge production \\ Políticas de producción de conocimiento en enfermería
}

\section{Isabel Amélia Costa Mendes', Maria Auxiliadora Trevizan', Josete Luzia Leite", Simone de Godoy', Carla Aparecida Arena Ventura'}

' Universidade de São Paulo. Escola de Enfermagem de Ribeirão Preto. Departamento de Enfermagem Geral e Especializada. Centro Colaborador da OMS para o Desenvolvimento da Pesquisa em Enfermagem. Ribeirão Preto-SP, Brasil.

"Universidade Federal do Rio de Janeiro. Escola de Enfermagem Anna Nery.

Departamento de Metodologia da Enfermagem. Rio de Janeiro-RJ, Brasil.

\section{RESUMO}

O Estado, por meio da administração direta e indireta, desempenha papel fundamental na construção de políticas públicas que implementem as diretrizes governamentais. Este estudo possui como objetivo geral apresentar síntese de investimentos para apoio à pesquisa em Enfermagem pelo Conselho Nacional de Desenvolvimento Científico e Tecnológico (CNPq) no período de 2001 a 2006. Utilizando dados secundários referentes aos investimentos em bolsas e fomento à pesquisa no período citado, são apresentados desafios e oportunidades existentes no processo de construção das políticas de produção do conhecimento em enfermagem. Apesar de todos os esforços envidados, há grandes lacunas a serem preenchidas para que realmente se efetive uma política de pesquisa em enfermagem no país.

Descritores: Enfermagem; Grupos de pesquisa; Pesquisa em enfermagem; Políticas públicas.

\section{ABSTRACT}

The state, through direct and indirect administration, plays a fundamental role in the construction of public policies to implement governmental guidelines. This study aimed at presenting a synthesis of investments to support Nursing research at National Council of Scientific and Technological Development from 2001 to 2006. Using secondary data regarding investments on fellowships and grants in the mentioned period, authors present challenges and opportunities in the process of building policies regarding producing knowledge in Nursing. Although the investments, there are gaps to be filled in order to really have a research policy in Nursing in the country.

Key words: Nursing; Research groups; Nursing research; Public policies.

\section{RESUMEN}

El Estado, por medio de la administración directa e indirecta, desempeña papel fundamental en la construcción de políticas públicas que implementen las directrices gubernamentales. Este estudio tuvo como objetivo general presentar síntesis de investimentos para apoyo a la investigación en Enfermería por el Consejo Nacional de Desarrollo Científico y Tecnológico en el período de 2001 hasta 2006. Utilizándose datos secundarios relacionados a las inversiones en becas y apoyo a la investigación en el período citado, son presentados desafíos y oportunidades existentes en el proceso de construcción de las políticas de producción de conocimiento en Enfermería. Además de los esfuerzos realizados, hay grandes brechas a ser llenadas para que realmente se torne en vigor una política de investigación en el país.

Palabras clave: Enfermería; Grupos de investigación; Investigación en enfermería; Políticas públicas.

Conferência proferida no 14º Seminário Nacional de Pesquisa em Enfermagem, Florianópolis-SC, 2007. 


\section{INTRODUÇÃO}

Da análise do termo política (1) podemos depreender, em uma síntese, dois de seus diferentes significados:

a) exposto em Ética, por Aristóteles ${ }^{(2)}$, política é a doutrina do direito e da moral. A investigação a respeito do que deve ser o bem e o bem supremo para o referido filósofo parece pertencer à política. Assim, com tal objetivo de estudo que fundamenta seu conceito, a política neste prisma é considerada a ciência mais importante e mais arquitetônica. Nessa compreensão da política vinculada à ética, Hobbes ${ }^{(3)}$ argumenta sobre os princípios utilizados no julgamento do que é justo e equânime ou de seus opostos, observando que a justiça alicerça as leis e as convenções.

b) exposto em Política, por Aristóteles ${ }^{(4)}$, política é a teoria do Estado. Com este significado, a política como ciência tem duas funções - (1) descrever a forma de estado ideal e (2) determinar a forma do melhor Estado possível em relação a determinadas circunstâncias.

No desenvolvimento desse conceito, é tríplice a tarefa da política: (1) investigar sobre o conceito fundamental do Estado; (2) indagar, através da história, o que os povos desejaram, produziram, obtiveram e por que obtiveram através da política; (3) com base nas duas tarefas acima referidas, buscar leis históricas e determinar imperativos morais ${ }^{(5)}$.

O conceito de política como teoria do Estado muitas vezes foi compreendido como força que lhe conferia o significado de divinização do Estado. O termo público, no sentido filosófico, é empregado para designar os conhecimentos disponíveis para qualquer indivíduo em circunstâncias apropriadas, desvinculadas da esfera pessoal. Sendo assim, público é aquilo de que todos podem participar igualmente, podendo, portanto, também ser expresso ou comunicado pela linguagem ${ }^{(6)}$.

Nesse contexto, a introdução da política pública como ferramenta das decisões de governo busca valorizar o caráter técnico no processo de formulação das políticas ${ }^{(7)}$.

\section{Pesquisa e saúde: a construção de uma interação}

$\mathrm{Na}$ cena política brasileira da atualidade um aspecto altamente positivo e animador é a sintonia que tem havido entre três Ministérios: Saúde, Educação e Ciência \& Tecnologia. A adoção desta política de harmonização e convergência de esforços tem provocado a abertura de amplos canais de entendimento, cooperação e operação conjuntas dos citados ministérios, sem precedentes na história recente.

Dirigindo nossa visão para o Ministério da Saúde (MS), depreende-se que o panorama da política de pesquisa em saúde encontra-se em fase de construção. Apesar dos esforços e estratégias implementados, a interação da pesquisa em saúde com a Política Nacional de Saúde no Brasil ainda deixa de utilizar todo o potencial existente.

Embora seja possível verificar uma evolução da pesquisa em saúde desde a metade do século XX, é preciso ressaltar que somente na $1^{\text {a }}$ Conferência Nacional de Ciência \& Tecnologia (C\&T) em Saúde, realizada em 1994, é que se estabeleceu que a política de pesquisa em saúde é um componente da Política Nacional de Saúde.
O Ministério da Saúde está chamando a si a responsabilidade de orquestrar esta grande tarefa de estruturar o esforço de pesquisa no setor, com a formulação explícita da política nacional de ciência, tecnologia e inovação em saúde, acompanhada de estratégias e mecanismos capazes de garantir seu desenvolvimento sustentável. Foi assim que se criou o Conselho de Ciência Tecnologia e Inovação, com a missão de coordenar as ações de C\&T do MS por meio da representação de todos os componentes do Ministério que realizam ou fomentam pesquisa. A partir de então, avanços na superação desse desafio estão sendo registrados, com a participação dos pesquisadores em saúde, além de outros atores.

Embora as lideranças da Enfermagem tenham feito algumas tentativas de estabelecer prioridades de pesquisa para a área, o que se nota é também o mesmo distanciamento da Política Nacional de Saúde observado nas outras carreiras da Grande Área da Saúde. Sendo assim, a Enfermagem ainda está por definir sua Política. Muitas tentativas ainda não atingiram os seus objetivos, porque tiveram como ponto de partida prioridades de pesquisa, ao invés da Política de Pesquisa. Com este direcionamento, houve uma reação corporativa em que nenhum grupo de pesquisa quis ver sua especificidade excluída da listagem, por receio de perda de prestígio e de oportunidades de financiamento. Devemos, portanto, inverter o caminho, traçando uma política alinhada à Política Nacional de Saúde e deixando que as prioridades sejam eleitas espontaneamente pelos pesquisadores com base em sua leitura da própria Política e dos instrumentos utilizados pelo MS e Ministério da Ciência e Tecnologia (MCT) para induzir e fomentar projetos que efetivamente contribuam para equacionar problemas relevantes para o funcionamento do sistema.

Na verdade, esta prática já vem sendo dada. A Política de Produção de Conhecimento em Enfermagem, ainda indefinida e não explicitada, está sendo determinada pelos instrumentos dos Ministérios da Saúde e da Ciência e Tecnologia e das Fundações de Apoio à Pesquisa nos estados da federação.

\section{OBJETIVO}

Com base na compreensão do cenário acima descrito e das acepções do termo política, abarcando a ética e a concepção de política pública como ferramenta para as decisões governamentais, este estudo possui como objetivo apresentar síntese de investimentos para apoio à pesquisa em Enfermagem pelo Conselho Nacional de Pesquisa (CNPq). Busca-se, portanto, apresentar alguns desafios e oportunidades existentes no processo de construção das políticas de produção do conhecimento em enfermagem.

\section{METODOLOGIA}

Estudo exploratório descritivo, cujos dados foram obtidos de relatórios de gestão do $\mathrm{CNPq}{ }^{\left({ }^{(8-14)}\right.}$ referentes aos investimentos em bolsas e fomento à pesquisa, no período de 2001 a 2006. Os dados foram extraídos dos relatórios e organizados, e são apresentados descritivamente em números absolutos e relativos, dispostos em tabelas. 


\section{RESULTADOS E DISCUSSÃO}

A análise exploratória dos dados deste estudo abrange, em primeiro lugar, os investimentos do CNPq à Pesquisa em Enfermagem no período citado.

O Conselho Nacional de Desenvolvimento Científico e Tecnológico - CNPq é uma agência do Ministério da Ciência e Tecnologia (MCT) e tem por finalidade: promover a pesquisa e o desenvolvimento científico e tecnológico, assim como a formação e capacitação de recursos humanos para pesquisa. A primeira finalidade é alcançada por um programa que é composto por ações estratégicas que apóiam e fomentam a geração e difusão de conhecimento, bem como a implantação e consolidação de núcleos de excelência.

Por meio da transferência de recursos dos Fundos Setoriais através de convênios com Ministérios para ações específicas de fomento à pesquisa, tem havido um maior aporte de recursos para contrato de projetos que se afinem com as políticas de C\&T e, no caso em análise, do Ministério da Saúde. No período de 2004/2006 foram contratados 1100 projetos qualificados nos 28 editais lançados pela parceria Departamento de Ciência e Tecnologia do Ministério da Saúde (DECIT/ MS) e Conselho Nacional de Desenvolvimento Científico e Tecnológico do Ministério de Ciência e Tecnologia (CNPq/ MCT) ${ }^{(15)}$. Estas estratégias de ação entre Ministérios e CNPq têm sido acompanhadas pelos pesquisadores de enfermagem que têm apresentado suas demandas. Analisando-se as ofertas de editais em comparação com a ocorrência de demandas, veremos que a Enfermagem está se apresentando com projetos em vários editais, o que revela que a área através de seus pesquisadores está atenta à política de Ciência e Tecnologia em Saúde. Assim, pode-se inferir que a área está mobilizada e respondendo aos estímulos da política de pesquisa em saúde. Estamos acompanhando as políticas públicas do setor e estamos respondendo a elas.

Além de responder à Política de Pesquisa em Saúde através de editais, a enfermagem há 30 anos vem marcando uma história de demanda às ofertas de balcão em alguns órgãos, mas com mais expressão no CNPq. Vamos nos ater à análise desta participação no período 2001 a 2006.

O programa de formação e capacitação de recursos humanos para pesquisa visa formar e qualificar pesquisadores, induzindo e ampliando a capacidade de resposta do sistema nacional de C\&T às demandas da sociedade, em termos de conhecimento e sua aplicação. Este programa, focado nos recursos humanos para a pesquisa é constituído por cinco ações: 1- concessão de bolsas de estímulo à pesquisa; 2- concessão de bolsas de formação e qualificação de pesquisadores; 3- concessão de bolsas de iniciação científica; 4- concessão de bolsas de desenvolvimento tecnológico e empresarial e sistema de gestão, 5- acompanhamento e avaliação da capacidade de recursos humanos. Na esfera deste trabalho, vamos nos ater à análise das três primeiras ações.

Considerando os seis anos em análise, o CNPq obteve recursos para investir em bolsas e no fomento à pesquisa (Tabela 1) que se mantiveram em patamares semelhantes no três primeiros anos (2001 a 2003). A partir de 2004, passou a totalizar um acréscimo de $27,4 \%$ em relação ao ano anterior, e um aumento de $59,6 \%$ dos recursos quando comparam-se os valores correspondentes aos anos de 2001 e 2006.

Para colocar em destaque especificamente a área de Enfermagem, calculou-se o percentual de participação frente a sua

Tabela 1 - Investimentos, em R\$ mil correntes, realizados pelo CNPq em bolsas e no fomento à pesquisa, segundo área específica e global, com percentuais calculados para a área de Enfermagem, com base nos valores específicos e totais das grandes áreas, 2001-2006.

\begin{tabular}{|c|c|c|c|c|c|c|c|c|c|c|}
\hline \multirow{3}{*}{ ANO } & \multicolumn{3}{|c|}{ Área específica } & \multicolumn{6}{|c|}{ Grandes áreas } & \multirow{3}{*}{$\begin{array}{c}\begin{array}{c}\text { Outros } \\
\text { investimentos }\end{array} \\
\text { R\$ mil correntes }\end{array}$} \\
\hline & \multirow{2}{*}{\begin{tabular}{|c|} 
Enfermagem \\
$\begin{array}{c}\mathbf{R} \$ \text { mil } \\
\text { correntes }\end{array}$ \\
\end{tabular}} & \multicolumn{2}{|c|}{ Ciências da Saúde } & \multicolumn{2}{|c|}{ Ciências da Vida } & \multicolumn{2}{|c|}{ Demais Áreas* } & \multicolumn{2}{|c|}{ TOTAL } & \\
\hline & & $\begin{array}{c}\mathbf{R} \$ \text { mil } \\
\text { correntes }\end{array}$ & $\begin{array}{c}\% \\
\text { ENF }\end{array}$ & $\begin{array}{c}\mathbf{R} \$ \text { mil } \\
\text { correntes }\end{array}$ & $\begin{array}{c}\% \\
\text { ENF }\end{array}$ & $\begin{array}{c}\mathbf{R} \$ \text { mil } \\
\text { correntes }\end{array}$ & $\begin{array}{l}\% \\
\text { ENF }\end{array}$ & $\begin{array}{c}\mathbf{R} \$ \text { mil } \\
\text { correntes }\end{array}$ & $\begin{array}{c}\% \\
\text { ENF }\end{array}$ & \\
\hline 2001 & 3.440 & 42.552 & 8,1 & 199.718 & 1,7 & 323.909 & 1,1 & 523.627 & 0,6 & 57.593 \\
\hline 2002 & 3.743 & 42.685 & 8,8 & 197.815 & 1,9 & 311.441 & 1,2 & 509.256 & 0,7 & 89.417 \\
\hline 2003 & 3.887 & 46.410 & 8,4 & 225.690 & 1,7 & 326.769 & 1,2 & 552.459 & 0,7 & 98.742 \\
\hline 2004 & 4.888 & 62.895 & 7,8 & 279.387 & 1,7 & 424.292 & 1,1 & 703.679 & 0,7 & 90.518 \\
\hline 2005 & 4.945 & 77.713 & 6,4 & 322.978 & 1,5 & 454.741 & 1,1 & 777.719 & 0,6 & 74.332 \\
\hline 2006 & 5.000 & 94.104 & 5,3 & 359.595 & 1,4 & 476.008 & 1,0 & 835.603 & 0,6 & 72.882 \\
\hline
\end{tabular}

*Demais áreas = Ciências da Natureza e Humanidades

Fonte: CNPq/AEI 
Tabela 2 - Investimentos, em R\$ mil correntes, realizados pelo CNPq em bolsas no país, segundo área específica e global, com percentuais calculados para a área de Enfermagem, com base nos valores específicos e totais das grandes áreas, 2001-2006.

\begin{tabular}{|c|c|c|c|c|c|c|c|c|c|c|}
\hline \multirow{3}{*}{ ANO } & \multicolumn{3}{|c|}{ Área específica } & \multicolumn{6}{|c|}{ Grandes áreas } & \multirow{3}{*}{$\begin{array}{c}\begin{array}{c}\text { Outros } \\
\text { investimentos }\end{array} \\
\text { R\$ mil correntes }\end{array}$} \\
\hline & \multirow{2}{*}{\begin{tabular}{c|} 
Enfermagem \\
$\mathbf{R} \$$ mil \\
correntes
\end{tabular}} & \multicolumn{2}{|c|}{ Ciências da Saúde } & \multicolumn{2}{|c|}{ Ciências da Vida } & \multicolumn{2}{|c|}{ Demais Áreas* } & \multicolumn{2}{|c|}{ TOTAL } & \\
\hline & & $\begin{array}{c}\text { R\$ mil } \\
\text { correntes }\end{array}$ & $\begin{array}{c}\% \\
\text { ENF }\end{array}$ & $\begin{array}{c}\text { R\$ mil } \\
\text { correntes }\end{array}$ & $\begin{array}{c}\% \\
\text { ENF }\end{array}$ & $\begin{array}{c}\text { R\$ mil } \\
\text { correntes }\end{array}$ & $\begin{array}{c}\% \\
\text { ENF }\end{array}$ & $\begin{array}{c}\mathbf{R} \$ \text { mil } \\
\text { correntes }\end{array}$ & $\begin{array}{c}\% \\
\text { ENF }\end{array}$ & \\
\hline 2001 & 2.965 & 29.858 & 9,9 & 132.728 & 2,2 & 207.515 & 1,4 & 340.243 & 0,9 & 27.157 \\
\hline 2002 & 3.127 & 29.840 & 10,5 & 134.755 & 2,3 & 208.445 & 1,5 & 343.200 & 0,9 & 31.746 \\
\hline 2003 & 3.384 & 31.121 & 10,9 & 152.310 & 2,2 & 242.292 & 1,4 & 394.602 & 0,8 & 31.788 \\
\hline 2004 & 3.844 & 38.083 & 10,1 & 193.456 & 2,0 & 298.274 & 1,3 & 491.730 & 0,8 & 43.709 \\
\hline 2005 & 3.856 & 42.374 & 9,1 & 208.437 & 1,8 & 319.755 & 1,2 & 528.192 & 0,7 & 49.424 \\
\hline 2006 & 4.309 & 49.183 & 8,8 & 233.198 & 1,8 & 367.482 & 1,2 & 600.680 & 0,7 & 45.221 \\
\hline
\end{tabular}

*Demais áreas = Ciências da Natureza e Humanidades Fonte: CNPq/AEI

Tabela 3 - Investimentos, em R\$ mil correntes, realizados pelo CNPq em bolsas no exterior, segundo área específica e global, com percentuais calculados para a área de Enfermagem, com base nos valores específicos e totais das grandes áreas, 2001-2006.

\begin{tabular}{|c|c|c|c|c|c|c|c|c|c|c|}
\hline \multirow{3}{*}{ ANO } & \multicolumn{3}{|c|}{ Área específica } & \multicolumn{6}{|c|}{ Grandes áreas } & \multirow{3}{*}{$\begin{array}{c}\begin{array}{c}\text { Outros } \\
\text { investimentos }\end{array} \\
\text { R\$ mil correntes }\end{array}$} \\
\hline & \multirow{2}{*}{\begin{tabular}{|c|} 
Enfermagem \\
R\$ mil \\
correntes \\
\end{tabular}} & \multicolumn{2}{|c|}{ Ciências da Saúde } & \multicolumn{2}{|c|}{ Ciências da Vida } & \multicolumn{2}{|c|}{ Demais Áreas* } & \multicolumn{2}{|c|}{ TOTAL } & \\
\hline & & $\begin{array}{c}\mathbf{R} \$ \text { mil } \\
\text { correntes }\end{array}$ & $\begin{array}{c}\% \\
\text { ENF }\end{array}$ & $\begin{array}{c}\mathbf{R} \$ \text { mil } \\
\text { correntes }\end{array}$ & $\begin{array}{c}\% \\
\text { ENF }\end{array}$ & $\begin{array}{c}\mathbf{R} \$ \text { mil } \\
\text { correntes }\end{array}$ & $\begin{array}{c}\% \\
\text { ENF }\end{array}$ & $\begin{array}{c}\mathbf{R} \$ \text { mil } \\
\text { correntes }\end{array}$ & $\begin{array}{c}\% \\
\text { ENF }\end{array}$ & \\
\hline 2001 & 95 & 3.043 & 3,1 & 13.376 & 0,7 & 29.800 & 0,3 & 43.176 & 0,2 & - \\
\hline 2002 & 181 & 4.628 & 3,9 & 18.700 & 1,0 & 36.974 & 0,5 & 55.674 & 0,3 & - \\
\hline 2003 & 209 & 3.115 & 6,7 & 13.954 & 1,5 & 26.321 & 0,8 & 40.275 & 0,5 & - \\
\hline 2004 & 231 & 2.538 & 9,1 & 12.353 & 1,9 & 24.889 & 0,9 & 37.242 & 0,6 & 110 \\
\hline 2005 & 127 & 1.998 & 6,3 & 9.473 & 1,3 & 19.923 & 0,6 & 29.396 & 0,4 & 1.075 \\
\hline 2006 & 166 & 1.869 & 8,9 & 7.767 & 2,1 & 17.184 & 1,0 & 24.951 & 0,7 & 333 \\
\hline
\end{tabular}

*Demais áreas = Ciências da Natureza e Humanidades Fonte: CNPq/AEI 
Tabela 4 - Investimentos, em R\$ mil correntes, realizados pelo CNPq em fomento à pesquisa, segundo área específica e global, com percentuais calculados para a área de Enfermagem, com base nos valores específicos e totais das grandes áreas, 2001-2006.

\begin{tabular}{|c|c|c|c|c|c|c|c|c|c|c|}
\hline \multirow{3}{*}{ ANO } & \multicolumn{3}{|c|}{ Área específica } & \multicolumn{6}{|c|}{ Grandes áreas } & \multirow{3}{*}{$\begin{array}{c}\text { Outros } \\
\text { investimentos }\end{array}$} \\
\hline & \multirow{2}{*}{\begin{tabular}{|c|} 
Enfermagem \\
$\begin{array}{c}\mathrm{R} \$ \mathrm{mil} \\
\text { correntes }\end{array}$ \\
\end{tabular}} & \multicolumn{2}{|c|}{ Ciências da Saúde } & \multicolumn{2}{|c|}{ Ciências da Vida } & \multicolumn{2}{|c|}{ Demais Áreas* } & \multicolumn{2}{|c|}{ TOTAL } & \\
\hline & & $\begin{array}{c}\mathbf{R} \$ \text { mil } \\
\text { correntes }\end{array}$ & $\begin{array}{c}\% \\
\text { ENF }\end{array}$ & $\begin{array}{c}\mathbf{R} \$ \text { mil } \\
\text { correntes }\end{array}$ & $\begin{array}{c}\% \\
\text { ENF }\end{array}$ & $\begin{array}{c}\mathbf{R} \$ \text { mil } \\
\text { correntes }\end{array}$ & $\begin{array}{c}\% \\
\text { ENF }\end{array}$ & $\begin{array}{c}\mathbf{R} \$ \text { mil } \\
\text { correntes }\end{array}$ & $\begin{array}{c}\% \\
\text { ENF }\end{array}$ & \\
\hline 2001 & 380 & 9.651 & 3,9 & 53.615 & 0,7 & 86.594 & 0,4 & 140.209 & 0,3 & 30.437 \\
\hline 2002 & 435 & 8.217 & 5,3 & 44.360 & 1,0 & 66.022 & 0,6 & 110.382 & 0,4 & 57.671 \\
\hline 2003 & 294 & 12.174 & 2,4 & 59.426 & 0,5 & 58.156 & 0,5 & 117.582 & 0,2 & 66.954 \\
\hline 2004 & 813 & 22.274 & 3,6 & 73.579 & 1,1 & 101.128 & 0,8 & 174.707 & 0,5 & 46.699 \\
\hline 2005 & 962 & 33.341 & 2,9 & 105.068 & 0,9 & 115.063 & 0,8 & 220.131 & 0,4 & 23.833 \\
\hline 2006 & 525 & 43.052 & 1,2 & 118.630 & 0,4 & 91.341 & 0,6 & 209.971 & 0,2 & 27.328 \\
\hline
\end{tabular}

*Demais áreas = Ciências da Natureza e Humanidades

Fonte: CNPq/AEI

área de conhecimento (Ciências da Saúde) e à sua grande área (Ciências da Vida), bem como aos totais obtidos pelas demais áreas e ao total geral de investimento em bolsas e fomento à pesquisa (Tabela 1).

Assim, considerando os percentuais referentes ao total de investimentos em bolsas e fomento à pesquisa (Tabela 1), a participação da enfermagem manteve-se estável quando se analisa o total obtido por todas as áreas (variações de 0,6 a $0,7 \%)$ e com as demais áreas (1,0 a 1,2\%) ao longo desses seis anos.

Entretanto, quando colocada frente à Grande Área e área específica, observa-se uma queda nos percentuais de participação da Enfermagem, especialmente nos 2 últimos anos, passando de 7,8\% (2004) para 6,4\% (2005) e 5,3\% (2006) frente ao montante recebido pela área Ciências da Saúde e de $1,7 \%$ (2004) para 1,5\% (2005) e 1,4\% (2006), quando cotejada com os recursos das Ciências da Vida.

Esses dados indicam que a Enfermagem quando comparada aos recursos destinados ao total destinados de áreas do conhecimento mantém-se estável nos percentuais de participação, mas perde espaço com a redução dos percentuais na distribuição dos recursos na sua própria área.

Na linha de ação Bolsas no país (Tabela 2), a Enfermagem obteve participação entre 0,7\% (em 2005 e 2006) a 0,9 (em 2001 e 2002) quando colocada frente ao total geral de recursos e entre $1,2 \%$ (em 2005 e 2006) a 1,5\% (em 2002) nas demais áreas.
Ao longo dos seis anos em análise, houve decréscimo da participação da Enfermagem nos últimos dois anos, tendo apresentado os menores índices de participação na sua área específica (Ciências da Saúde) com 9,1\% (em 2005) e 8,8\% (em 2006), e na Grande Área Ciências da Vida com 1,8\% nos anos de 2005 e 2006.

$\mathrm{Na}$ análise isolada do investimento em Bolsas no Exterior (Tabela 3), a Enfermagem frente ao obtido pela área Ciências da Saúde melhora a sua participação a partir do ano de 2003 $(6,7 \%)$, com o dobro de participação quando comparado com os 2 anos anteriores, passando para 9,1\% em 2004, mantendo-se em patamares semelhantes especialmente no ano de 2006 (8,9\%).

No âmbito das Ciências da Vida, a participação da Enfermagem no investimento em bolsas no exterior variou entre $0,7 \%$ (2001) a 2,1\% (2006) apontando para uma evolução positiva.

O mesmo ocorre em relação à participação frente às demais áreas (0,3\% em 2001 para 1,0\% em 2006) e frente ao total de recursos investidos nessa grande linha de ação (passou de 0,2\% em 2001 para 0,7 em 2006).

Quanto ao Fomento à Pesquisa (Tabela 4) observa-se decréscimo da participação da Enfermagem uma vez que alcançou uma elevação em 2002 (5,3\%) e mais recentemente, em 2006, passou para 1,2\%, a menor participação dos anos em análise.

No contexto das Ciências da Vida, em 2006 ocorreu a menor participação $(0,4 \%)$ tendo chegado a 1,1\% em 2004. Na 
Tabela 5 - Investimentos, em R\$ mil correntes, realizados pelo CNPq na Área de ENFERMAGEM, em Bolsas e no Fomento à Pesquisa por modalidade, 2001-2006.

\begin{tabular}{|c|c|c|c|c|c|c|c|c|c|c|c|c|}
\hline \multirow{2}{*}{$\begin{array}{l}\text { Grande Linha de Ação/ } \\
\text { Modalidade }\end{array}$} & \multicolumn{2}{|c|}{2001} & \multicolumn{2}{|c|}{2002} & \multicolumn{2}{|c|}{2003} & \multicolumn{2}{|c|}{2004} & \multicolumn{2}{|c|}{2005} & \multicolumn{2}{|c|}{2006} \\
\hline & $\mathbf{R} \$$ & $\%$ & $\mathbf{R} \mathbf{S}$ & $\%$ & $\mathbf{R} \$$ & $\%$ & $\mathbf{R} \$$ & $\%$ & $\mathbf{R} \$$ & $\%$ & $\mathbf{R} \$$ & $\%$ \\
\hline \multicolumn{13}{|l|}{ Bolsas no País } \\
\hline Produtividade em Pesquisa & 910 & 26,5 & 905 & 24,2 & 1.242 & 31,9 & 1.642 & 33,6 & 1.732 & 35,1 & 1.832 & 36,6 \\
\hline Doutorado & 564 & 16,4 & 552 & 14,8 & 577 & 14,8 & 576 & 11,8 & 564 & 11,4 & 769 & 15,4 \\
\hline $\begin{array}{l}\text { Pós-Doutorado e } \\
\text { Pós-Doutorado Sênior }\end{array}$ & - & - & - & - & - & - & 31 & 0,6 & 21 & 0,4 & 18 & 0,4 \\
\hline Mestrado & 337 & 9,8 & 333 & 8,9 & 261 & 6,7 & 371 & 7,6 & 446 & 9,0 & 454 & 9,1 \\
\hline Iniciação Científica & 374 & 10,9 & 435 & 11,6 & 400 & 10,3 & 313 & 6,4 & 225 & 4,6 & 204 & 4,0 \\
\hline Iniciação Científica/PIBIC & 537 & 15,6 & 618 & 16,5 & 621 & 16,0 & 643 & 13,1 & 723 & 14,6 & 906 & 18,1 \\
\hline Apoio Técnico à Pesquisa & 201 & 5,8 & 259 & 6,9 & 263 & 6,8 & 216 & 4,4 & 135 & 207 & 100 & 2,0 \\
\hline Outros $(*)$ & 42 & 1,2 & 24 & 0,7 & 20 & 0,5 & 53 & 1,1 & 9 & 0,2 & 28 & 0,6 \\
\hline Subtotal & 2.965 & 86,2 & 3.126 & 83,6 & 3.384 & 87,0 & 3.845 & 78,6 & 3.855 & 78,0 & 4.308 & 86,2 \\
\hline \multicolumn{13}{|l|}{ Bolsas no Exterior } \\
\hline Doutorado & 92 & 2,7 & 110 & 2,9 & 94 & 2,4 & 104 & 2,1 & 94 & 1,9 & 84 & 1,7 \\
\hline Doutorado Sanduíche & - & - & - & - & 43 & 1,1 & 38 & 0,8 & - & - & - & - \\
\hline Estágio Junior/Sênior & - & - & - & - & - & - & - & - & - & - & 19 & 0,4 \\
\hline Pós-Doutorado & 3 & 0,1 & 70 & 1,9 & 72 & 1,9 & 89 & 1,8 & 33 & 0,7 & 63 & 1,2 \\
\hline Subtotal & 95 & 2,8 & 180 & 4,8 & 209 & 5,4 & 231 & 4,7 & 127 & 2,6 & 166 & 3,3 \\
\hline \multicolumn{13}{|l|}{ Fomento à Pesquisa } \\
\hline $\begin{array}{l}\text { Apoio a Publicações } \\
\text { Científicas }\end{array}$ & 38 & 1,1 & 35 & 1,0 & 44 & 1,1 & 167 & 3,4 & 60 & 1,2 & - & - \\
\hline $\begin{array}{l}\text { Apoio ao Desenvolvimento } \\
\text { Científico e Tecnológico }\end{array}$ & - & - & - & - & - & - & 211 & 4,3 & 90 & 1,8 & - & - \\
\hline Auxílio Pesquisa & 148 & 4,3 & 135 & 3,6 & 166 & 4,3 & 279 & 5,7 & 607 & 12,3 & 400 & 8,0 \\
\hline Auxílio Pesquisa A1 & - & - & 169 & 4,5 & - & - & 46 & 1,0 & 135 & 2,7 & - & - \\
\hline $\begin{array}{l}\text { Auxílio Pesquisador } \\
\text { Visitante }\end{array}$ & 5 & 0,1 & 5 & 0,1 & - & - & - & - & - & - & - & - \\
\hline $\begin{array}{l}\text { Participação em Eventos } \\
\text { Científicos }\end{array}$ & 55 & 1,6 & 8 & 0,2 & - & - & 6 & 0,1 & 15 & 0,3 & 29 & 0,6 \\
\hline $\begin{array}{l}\text { Promoção de Eventos } \\
\text { Científicos }\end{array}$ & 133 & 3,9 & 82 & 2,2 & 85 & 2,2 & 105 & 2,2 & 55 & 1,1 & 96 & 1,9 \\
\hline Subtotal & 379 & 11,0 & 434 & 11,6 & 295 & 7,6 & 814 & 16,7 & 962 & 19,4 & 525 & 10,5 \\
\hline Total & 3.439 & 100 & 3.740 & 100 & 3.888 & 100 & 4.890 & 100 & 4.944 & 100 & 4.999 & 100 \\
\hline
\end{tabular}

$R \$$ - Reais mil correntes

(*) Apoio Técnico em Extensão, Desenvolvimento Tecnológico Industrial, Iniciação Tecnológica Industrial, Desenvolvimento Científico Regional. 
visão global e quando colocada frente às demais áreas, a Enfermagem apresentou melhor participação em 2004 e 2005 $(0,8 \%)$ e no investimento total, em $2004(0,5 \%)$.

$\mathrm{A}$ análise do investimento destinado à Enfermagem aponta que das grandes linhas de ação, priorizou-se a de Bolsas no País.

O fato é que, apesar da evolução, a Pesquisa em Enfermagem precisa aparecer com maior destaque na agenda nacional. Ao Ministério da Saúde devem ser endereçadas informações sobre resultados de pesquisa. Neste âmbito do governo federal é preciso que se demonstre como a aplicação de resultados de pesquisa nos serviços pode interferir na melhoria do atendimento às necessidades da sociedade.

O Ministério da Saúde também precisa receber sinais claros e ter ciência de uma Política Nacional de Produção de Conhecimento de Enfermagem que, assentada na Política Nacional de Saúde, marque claramente a busca de convergências e, através delas, a meta de alcance de respostas aos problemas, às propostas de ação e inovação nos serviços.

Os pesquisadores da área enfermagem no Brasil precisam ter clareza da importância de sua vinculação à Política Nacional de Saúde e endereçar seus projetos para problemas para os quais o Ministério da Saúde busca soluções. Da mesma forma, devem estar alinhados às Políticas e Estratégias da Organização Mundial da Saúde. Este alinhamento é crucial para que as energias sejam direcionadas a projetos capazes de trazer soluções que façam diferença no sistema de saúde e, em conseqüência, tragam um diferencial para a área de Enfermagem com reflexos positivos internos e externos.

$\mathrm{O}$ distanciamento que se observa, em relação à Política Nacional de Saúde, e por parte dos enfermeiros pesquisadores não se restringe a esta área.

Mas, de todo modo, os cientistas-enfermeiros precisam mostrar tudo o que já conseguiram mesmo nas condições adversas em que trabalham, em termos de ausência de uma política universitária que subsidie a produção de conhecimento nas escolas de enfermagem por meio de uma logística semeIhante àquela disponibilizada por essas mesmas universidades aos cientistas de áreas bem estabelecidas. Especialmente em termos funcionais, há uma desigualdade oriunda da época em que a atividade científica não era desenvolvida por enfermeiros. Por isso, não precisava de técnicos de apoio à pesquisa nos quadros institucionais de enfermagem. Quando, por força estatutária, os docentes de enfermagem começaram a dedicar-se à pesquisa, enfrentaram e superaram condições limitantes, fazendo uso de estratégias que demandavam enorme esforço e dispêndio de energia e de recursos próprios, preparando e coordenando o trabalho de voluntários que se dispusessem a colaborar com o trabalho do pesquisador. Improvisações, exacerbação de criatividade, dedicação e solidariedade - componentes próprios do perfil do enfermeiro - serviram para contornar dificuldades e atingir objetivos. Mas, é preciso que miremo-nos no exemplo daqueles que contam com o respaldo institucional para facilitarmos nosso trabalho, para alcançarmos melhores resultados canalizando energias para o processo de criação e de aplicação, convertendo resultado em inovação, sempre em consonância com a realidade de saúde em que nos encontramos e em sintonia com a política de saúde do país.
Ou seja, sem infraestrutura física e funcional para apoiar a atividade científica, o pesquisador brasileiro da área de enfermagem emprega muito mais tempo e recursos próprios para desenvolver seu projeto, enquanto os de outras áreas têm todas as facilidades à mão, o que os coloca em posição muito vantajosa para submeter projetos e captar cada vez mais recursos. Este fator (demanda qualificada) interfere na distribuição de recursos nos órgãos de fomento, que se baseiam via de regra no critério de volume de demanda para o cálculo de divisão dos recursos por áreas e subáreas (15-18).

A solução provisória que os pesquisadores de enfermagem encontraram, e fizeram por merecer, foi através de bolsas de Apoio Técnico à Pesquisa do CNPq, modalidade esta regularmente disponibilizada até 2004 através de cotas aos Comitês de Assessoramento, mediante demanda. Em função da demanda, a representação de área convenceu o órgão de que esta modalidade era primordial para a Enfermagem, pelas peculiaridades da própria área no contexto das Universidades. Foi assim que, embora insuficiente para a própria área, se fez crescer significativamente o número de cotas em comparação a outras da área da saúde. Mas a partir de 2004, com a oferta por meio de editais, e não mais por balcão, a enfermagem viu reduzir-se um percentual considerável deste recurso humano em $2006 \mathrm{em}$ relação a 2002. Cumpre lembrar que a extinção de bolsas de Apoio Técnico por cotas foi aproveitada pela área para converter os recursos provisionados para outra modalidade também essencial, cuja demanda qualificada cresceu consideravelmente, mas, com a limitação financeira não alcançavam prioridade de atendimento. O repasse de recursos de cotas de Apoio Técnico e Iniciação Científica em 2002 para Produtividade em Pesquisa foi estratégia importante para que os recursos, em provimento na área, nela permanecessem. Esta mudança de estratégia do $\mathrm{CNPq}$ em relação a esta modalidade (Apoio Técnico) serviu, uma vez mais, para apontar à Enfermagem brasileira que temos que usar este recurso como uma alternativa e não como solução. Mesmo porque aqueles pesquisadores que foram contemplados com cotas desta natureza sempre se defrontaram com o problema de rotatividade, uma vez que não tendo vínculo empregatício, a oferta não se torna suficientemente atrativa para sua retenção nos grupos de pesquisa.

Em conseqüência desta rotatividade, os líderes desses grupos devem arcar com dedicação a treinamentos constantes a esses recursos-chave e trabalhar sempre com a perspectiva de provisoriedade em termos da logística.

É preciso, pois, que as Universidades entendam que também os seus Departamentos/Escolas de Enfermagem necessitam de técnicos de apoio a pesquisa, à semelhança dos quadros existentes nos outros cursos da área da saúde e das outras áreas.

Este é um recurso que promove uma diferença crucial no ritmo da produtividade. E os nossos docentes pouco ou nada têm se mobilizado no sentido de impor a demonstração desta necessidade e no sentido de apresentar demanda justificada, reivindicando e insistindo no atendimento por parte das Reitorias.

Trata-se de uma questão de luta por igualdade de direitos e de tratamento no contexto de cada instituição. Trata-se da necessidade de se invocar o princípio da equidade. E esta luta tem que ser travada na internalidade de cada uma destas instituições, 
por suas lideranças, e no íntimo de cada pesquisador, mas também se impõe uma mobilização suprainstitucional, congregando estes líderes para um trabalho pró-crescimento da Enfermagem. Esta causa pode ser também abraçada pela Associação Brasileira de Enfermagem, através do Centro de Estudos e Pesquisas em Enfermagem-CEPEn.

\section{CONSIDERAÇÕES FINAIS}

Considerando o papel do Estado na construção de políticas públicas que visem o "bem comum" por meio de seus órgãos diretos e indiretos, este estudo apresentou a evolução das políticas implementadas pelo CNPq na área da Enfermagem.

Apesar de todos os esforços envidados, existem ainda grandes lacunas a serem preenchidas para que realmente se efetive uma política de pesquisa em enfermagem no país. Nesse sentido, a atuação conjunta de enfermeiros e suas lideranças, as instâncias de poder dentro das Universidades, as associações e representações de Enfermagem em órgãos públicos e organizações privadas é crucial para que se construa um direcionamento na pesquisa em enfermagem que esteja em consonância com as reais necessidades vivenciadas pela nossa profissão no âmbito do Sistema de Saúde Brasileiro. Somente assim teremos condições de construir uma Política que inclua e favoreça as condições pró-produção de conhecimento nas instituições de enfermagem, onde se desenvolvem pesquisas, que servirá como instrumento de respaldo fortalecedor das reivindicações por recursos que cada instituição apresentar às autoridades competentes, uma Política que impulsione os pesquisadores em busca de oportunidades, desafios, aberturas, estratégias e possibilidades.

Muito se conseguiu até aqui, mas é preciso que se descortinem novas perspectivas. Na medida em que se conquistam novos espaços, amplia-se e fortalece-se a imagem profissional, distribuindo-se as demandas, a capacidade de ampliação do investimento em nossos projetos é favorecida, fortalece-se o moral daqueles cujos projetos foram qualificados e um espírito de conquista vai se refletindo em sua rede de relacionamentos. Este caminhar tem o potencial de agregar valor e introduzir mudanças positivas na cultura profissional.

\section{Agradecimento}

Ao $\mathrm{CNPq} / \mathrm{COSAU}$ pelo apoio logístico e financeiro oferecidos para a realização da presente pesquisa.

\section{REFERÊNCIAS}

1. Abbagnano N. Dicionário de Filosofia $1^{\mathrm{a}}$ ed. São Paulo: Martins Fontes, 2007.

2. Aristóteles. Ética a Nicômaco. São Paulo: Abril Cultural, 1979.

3. Hobbes T. Do cidadão. São Paulo: Martins Fontes, 1998.

4. Aristóteles. Política. $1^{\mathrm{a}}$ ed. São Paulo: Martin Claret, 2006.

5. Treitschke HGV. Politics. $1^{\text {st }}$ ed. Ams Pr Inc, 1988.

6. Kant I. Crítica da razão pura. $1^{\text {a }}$ ed. São Paulo: Martin Claret, 2009.

7. Souza C. Políticas Públicas: uma revisão da literatura. Sociologias 2006;8(16): 20-45.

8. Ministério da Ciência e Tecnologia/Conselho Nacional de Desenvolvimento Científico e Tecnológico. Relatório de Gestão Institucional. Brasília: CNPq, 2001. Disponível em http://www.cnpq.br/cnpq/docs/relatorio_gestao_2001.pdf.

9. Ministério da Ciência e Tecnologia/Conselho Nacional de Desenvolvimento Científico e Tecnológico. Relatório de Gestão Institucional. Brasília: CNPq, 2002. Disponível em http://www.cnpq.br/cnpq/docs/relatorio gestao_2002.pdf.

10. Ministério da Ciência e Tecnologia/Conselho Nacional de Desenvolvimento Científico e Tecnológico. Relatório de Gestão Institucional. Brasília: CNPq, 2003. Disponível em http://www.cnpq.br/cnpq/docs/relatorio_gestao_2003.pdf.

11. Ministério da Ciência e Tecnologia/Conselho Nacional de Desenvolvimento Científico e Tecnológico. Relatório de Gestão Institucional. Brasília: CNPq, 2004. Disponível em http://www.cnpq.br/cnpq/docs/relatorio gestao 2004.pdf.

12. Ministério da Ciência e Tecnologia/Conselho Nacional de Desenvolvimento Científico e Tecnológico. Relatório de Gestão Institucional. Brasília: CNPq, 2005. Disponível em http://www.cnpq.br/cnpq/contas/2005/docs/relatorio_gestao_2005.pdf.

13. Ministério da Ciência e Tecnologia/Conselho Nacional de Desenvolvimento Científico e Tecnológico. Relatório de Gestão Institucional. Brasília: CNPq, 2006. Disponível em http://www.cnpq.br/cnpq/contas/2006/docs/relatorio_gestao_2006.pdf.

14. Ministério da Ciência e Tecnologia/Conselho Nacional de Desenvolvimento Científico e Tecnológico. Relatório Institucional do CNPq 2003-2006. Brasília: CNPq, 2006. Disponível em http://www.cnpq.br/cnpq/docs/relatorio_ 20032006.pdf.

15. Leite JL, Mendes IAC. Pesquisa em enfermagem e seu espaço no CNPq. Esc Anna Nery Rev de Enferm 2000;4(3): 389-94.

16. Leite JL, Trezza MCS, Santos RM, Mendes IAC, Felli VEA. Os projetos de pesquisa de enfermagem no CNPq: seu percurso, suas temáticas, suas aderências-1998/2000. Rev Bras Enferm 2001;54(1): 81-97.

17. Marziale MHP, Mendes IAC. O investimento em pesquisas na área da saúde: termos de referência para o desenvolvimento científico e tecnológico brasileiro. Rev Latino-Am Enfermagem [online]. 2006 Abr [citado 2011 Maio 17]; 14(2): 149-50. Disponível em: http://www. scielo.br/scielo.php?script =sci_arttext\&pid =S0104$-11692006000200001 \& \operatorname{lng}=$ pt.

18. Mendes IAC, Leite JL, Santos RM, Trevizan MA. Classificação dos pesquisadores/consultores da área de enfermagem no CNPQ: contribuição para um banco de dados. Rev Bras Enferm 2003;56(5): 488-93. 